\title{
Slow Computing
}

\author{
Alistair Fraser ${ }^{1}$ and Rob Kitchin ${ }^{2}$
}

1. Department of Geography, Maynooth University, County Kildare, Ireland

2. MUSSI, Maynooth University, County Kildare, Ireland

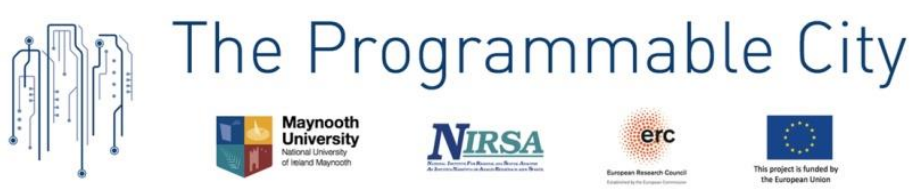

The Programmable City Working Paper 36

http://progcity.maynoothuniversity.ie/

6 December 2017

Prepared as a position paper for 'Slow computing: A workshop on resistance in the algorithmic age', Maynooth, Dec 14th 2017. http://progcity.maynoothuniversity.ie/2017/11/slow-computing-aworkshop-on-resistance-in-the-algorithmic-agel

Published as an open access pre-print on SocArXiv: https://osf.io/preprints/socarxiv/rmxfk

\begin{abstract}
In this short position paper we examine some of the dimensions and dynamics of the algorithmic age by considering three broad questions. First, what are the problematic consequences of life mediated by 'algorithm machines'? Second, how are individuals or groups and associations resisting the problems they encounter? Third, how might the algorithmic age be re-envisioned and re-made in more normative terms? We focus on two key aspects of living with ubiquitous computing, 'acceleration' and 'data grabbing,' which we contend are two of the most prominent and problematic features of the algorithmic age. We then begin to shed light on the sorts of practices that constitute slow computing responses to these issues. In the conclusion, we make the case for a widescale embrace of slow computing, which we propose is a necessary step for society to make the most of the undeniable opportunities for radical social change emerging from contemporary technological developments.
\end{abstract}

Key words: slow computing, algorithmic governance, ubiquitous computing, acceleration, big data, resistance 


\section{Introduction}

We are moving through the early stages of the new 'algorithmic age,' a point in space-time in which human life is increasingly mediated by firms and institutions using 'algorithm machines' - that is, software-enabled technologies that are also increasingly networked - to transform and capture markets and governance (Gillespie 2014). The algorithmic age raises numerous new questions for social scientists interested in economic production, political governance, and social difference. The empirical issues and conceptual architectures used to understand firm behaviour and intent, governmental strategies and institutional organisation, individual and group action are now wrapped-up with the existence, prevalence, and nuanced intricacies of algorithms (see Kitchin and Dodge 2011; Amoore 2013; Pasquale 2015). Regardless of specific research foci, understanding 'the social' requires finding ways of coming to terms with and developing adequate conceptualizations of algorithms and the code, data, networks, and socio-technical assemblages that make it possible for so much of contemporary human life to involve - and at a growing rate to depend on - computational calculations to mediate, augment, and supplement our everyday actions (Kitchin 2017).

While many treatises on the algorithmic age celebrate the power of computation - that 'algorithm machines' enable complex tasks to be tackled that would be all but impossible by hand or analogue machines; can significantly reduce costs and increase turnover and profit through automation; and create new services/products - others question whether their supposed benefits outweigh their pernicious effects, or these can be bought into a more balanced arrangement. With regards to the latter, in this short position paper we examine some of the dimensions and dynamics of the algorithmic age by answering three broad questions. First, what are the problematic consequences of living with and through algorithms? Second, how are individuals or groups and associations resisting the problems they are encountering? Third, how might the algorithmic age be re-envisioned and re-made so it is not driven primarily from an instrumental perspective (solving specific technicallyframed problems), but rather by normatively-framed ideas and ideals of fairness, equity, justice, citizenship, democracy?

Regarding the first question, we find answers from across the quickly-evolving 'software studies', 'critical data studies' and 'platform studies' literature. Although most critical analyses of algorithmic life will inevitably find aspects to applaud - software that eases distanciated communication; apps that tweak transportation systems for the better there are also developments that prompt concerns about the effects of 'disrupted' markets (Manyika et al. 2011), the erosion of privacy (Elwood and Leszczynski 2011; Kitchin 2016), 
the controlling or nudging of behaviour (Amoore 2013), the creation of new forms of governmentality (Deleuze 1992; Lyon 2007), or the capacity for algorithms to alter subjectivities (Kramer et al., 2016; McIlwain, 2017). Whether or not an individual is bound up with algorithmic life via their daily 'devicing,' decisions in distant corporate headquarters and government offices are mobilized through algorithms, data assemblages, sensors, and interfaces. Algorithms alter the quotidian possibilities and constraints individuals encounter. For so long as democratic oversight and control of these decisions and processes is lacking, there is much to fault with the manner in which the algorithmic age is taking shape.

These problems therefore beg our second question about what individuals or groups and associations are doing to negotiate and resist the problems they encounter. In this regard, and in line with parallel concepts of 'slow food' (Miele and Murdoch 2002), 'slow scholarship' (Mountz et al. 2015) and 'slow urbanism' (Datta and Shaban 2017), we advance the notion of 'slow computing,' which we propose is an apt characterisation of the actions a wide range of people are pursuing to oppose, evade, alter, or otherwise navigate their way around emerging problems, such as those noted above and many others. And this leads to our third and more normative question regarding a re-envisaging of the algorithmic age through the principles and practices of slow computing; that is, a form of computing that works in the service of citizens to promote their wellbeing and protect their rights, rather than prioritizing the aims and values of corporations and states.

In the rest of this paper, then, our aim is to demonstrate why slow computing deserves attention and to begin tracing an outline of slow computing thinking and practices. In the next section, we discuss the machinations of what we refer to as 'acceleration' and 'grabbing,' which we argue are two of the most prominent and problematic features of the algorithmic age. We then begin to shed light on the sorts of practices that constitute slow computing responses to these problems. Finally, in the conclusion, we make the case for a widescale embrace of slow computing, which we propose is a necessary step for human society to make the most of the undeniable opportunities for radical social change emerging from contemporary technological developments.

\section{On the machinations of 'acceleration' and 'grabbing'}

As we move further and deeper into the algorithmic age, two broad and interrelated features stand out. First, there is 'acceleration,' which refers to the increasing pace of social life, as well as other timing effects such as temporal fragmentation and densification, and which effectively pulls individuals and groups almost-inexorably into the orbit of technically 
mediated action. Second, there is the process of 'grabbing,' a term we use to capture the broad and dynamic processes via which firms and institutions construct vast monetizable and governmental data assemblages.

\section{Acceleration}

It is hard to avoid the sensation that the temporality of contemporary life has been reconfigured by ICTs; that the use of networked technologies is creating a faster and busier world by enabling tasks to be undertaken more efficiently. Time scholars note a number of trends (see Hassan and Purser 2007; Rosa 2015; Wacjman 2015). First, there has been a speeding up of the delivery of services through internet access, obviating the need for travel and physically queuing and enabling the swift provision of information. Second, always-on computation and communication have led to people being 'always-everywhere available' (Green 2002) and the time shifting of activities to formerly unavailable times (e.g., 'dead time', such as waiting for a bus, can be made 'productive time' by colonizing it with other activities such as answering email) and more flexible scheduling of activities (e.g., on-the-fly diary alterations due to unfolding events, such as people being delayed or unexpected meetings). Third, ICTs change the tempo of events by enabling immediate, distanciated response, simultaneous occurrences, multitasking and the interleaving of activities (e.g., performing several tasks simultaneously rather than sequentially). Fourth, ICTs create a shortening in the time lag between action and event, enabling real-time systems and instantaneous response, whether through social media, traffic control systems, or dozens of other media/systems. Collectively, these processes are producing 'faster' and more temporally-flexible subjects and a fragmentation of everyday life into a kaleidoscope of denser, smaller units of time of diverse activities. Moreover, they often seek to anticipate and produce future outcomes.

Not only are temporal relations faster and denser, then, but the rate of technical and social change seems to have accelerated with a succession of new innovations. Rosa (2003) describes three forms of acceleration: the acceleration of the pace of life, in which there is a decrease in the time needed to undertake everyday processes and actions of production, reproduction, communication and transportation; technological acceleration, in which there is a speeding up of technical processes such as the rate of data processing, the speed of transport, the rapidity of communication, and the work pace of manufacturing machines; and acceleration of social change, in which social relations (such as attitudes, values, practices, habits), structures (such as communities, workplaces) and institutions (such as public 
services) increasingly lack stability and constantly mutate. This new accelerated modernity, Rosa (2015: 213) argues, draws on key 'accelerative movements' - the development of the Internet, post-1989 political change in Europe, the emergence of post-Fordist flexible accumulation - and pushes at the limits of what the state, the self, politics, and culture can effectively navigate without encountering severe difficulty or crisis.

As a result, paradoxes of acceleration emerge. Most notably, although often designed to help people manage and cope with the compression, densification and fragmentation of time, ICTs compress and further fragment time (Crang 2007). ICTs often produce ever-moreextended and complex network of tasks to attend to, producing time crunches and time stresses in which it never feels there are enough hours in the day to all the things needed. The fast pace of social life can thus generate a 'feeling of a loss of autonomy that is manifested in the disappearance of any possibility of control and the erosion of opportunities to shape one's own affairs' (Rosa 2015: 294), which in turn can encourage a sense of fatalism, albeit tied-in with new post-secular political movements that claim authority to regain control over time (Trump's 'Make America Great Again' comes to mind).

A critical observation is that the reconfiguring of temporal relations relies on the pervasive role of algorithmic processes in contemporary life. One central purpose of society's turn toward opaque and complex algorithms is to speed up calculative moments, thereby offering individuals, firms, and institutions greater scope to construct pathways toward the future. But the same opportunity to make rapid, even real-time, decisions also puts immense strain on social actors. This is not just a matter of the aforementioned sense of a loss of autonomy and control. Rather, accelerated life in the algorithmic age entails a depth and intensity of mixed emotions - hesitancy, ambivalence, confusion - because social action, which always occurs via connections with overlapping networks (Ettlinger 2003) and chains of social relations, can require reference to multiple sources of information and involve anticipating and making calculations about numerous possible futures, the outlines of which can be rendered quickly and at relatively low cost. The possibilities inherent in connected algorithms across dispersed platforms and constituent units will often be simply capitalized upon and made into something productive and/or enjoyed. However, a persistent sense of greater uncertainty - maybe the 'red' traffic zone on this map will turn 'green'; maybe a competing firm suddenly tweaks its code in a way that reduces our advertising revenue gives rise to the mixed emotions associated with living in the accelerated moments of the algorithmic age. 
In turn, efforts to plan or make specific adjustments become bound up with algorithmic processing controlled by firms and institutions pursing their 'inter-hesitant' futures. And because social actors must turn to today's central platforms (or technological ecosystems) for information or a sense of guidance, a new shared milieu of accelerated and intense uncertainty is established, which 'big data' analyses might try to make sense of but always in the face of new sources of data emerging to confound conclusions. As such, as social life in the algorithmic age is drawn into the orbit of the technology firms claiming to simplify or de-mystify widespread confusion about what the future holds, our accelerated actions and anticipations increasingly pivot on how we make sense of our proximity to and intimacy with the intentions and imaginaries of those who exert some control over the algorithms shaping life around us.

\section{Grabbing}

As social life accelerates, then, individuals become increasingly reliant on proliferating platforms and their constituent units. Engaging in social life - having a job, knowing where a meeting or party is, hearing family news - brings us all into contact with, and therefore exposes us to the whims and motivations of, today's leading technology firms and, subsequently, a wide variety of other manufacturing and services firms offering goods and services via close integration with technology platforms. There is much to be said for many of these platforms and units: the quality of results from Google's search engine or the extraordinary capacity to connect socially via a platform such as Facebook are developments that billions of technology users have welcomed and enjoyed. Numerous other platforms, or specific services such as WiFi or mobile broadband, are popular, embraced, and indeed in some instances have reached into our lives to such an extent that many of us would dread going without them. However, a central feature of this emerging relationship between individuals and technology firms concerns the 'grabbing' by the latter of vast quantities of data about the lives, tastes, identities, spaces, and temporalities of individuals.

Otherwise conceptualized as 'data colonialism' (Thatcher et al., 2016) one dynamic of this process of grabbing data from technology users takes shape because users 'sign' end-user license agreements that give service providers legal authority to gather, collate, aggregate, and monetize data, most often by selling advertisements on web sites or mobile apps, or by selling the data to data brokers who seek to consolidate and repackage data into new products and offer a variety of data services (e.g., people and place profiling, search and background checks; assessments of credit worthiness; socially and spatially sorting individuals; provision 
of tracing services; undertaking predictive modelling as to what individuals might do under different circumstances or how much risk a person constitutes; creating micro-target advertising and marketing campaigns; supplying detailed business analytics). One such data brokerage company, Acxiom, is reputed to have constructed a databank concerning 500 million active consumers worldwide, with about 1,500 data points per person, and claims to be able to provide a '360-degree view' on consumers (meshing off-line, online and mobile data) (Singer 2012). Many of the world's other 7 billion inhabitants are captured in the databanks of other data brokers and databases generated by the state. Such capture can be extensive, for example, the Dutch Data Protection Authority estimated that the average Dutch citizen was included in 250-500 commercial and state databases, with more socially active people included in up to 1000 databases (Koops 2011).

Fine-grained, personalized data has become a very valuable resource and vast fortunes have been accumulated by technology firms offering 'free' services in exchange for data. Although shareholders of those firms have certainly reaped significant rewards, a large proportion of the accumulated profits have been immediately re-invested in research and development to expand the range and depth of algorithms and find new ways of grabbing and monetizing data, with some leading firms edging toward a position where their stores of data can be used to facilitate new machine learning infrastructures that propel artificial intelligence into the daily lives of technology users.

But even when individuals have not given their consent to have data about their lives used in this manner - that is, beyond the specificities of data colonialism - widely-used practices in the algorithmic age involve grabbing data (see Kitchin 2016). In public space, cameras use facial recognition technology to 'track' or identify urban residents; and sensors count passing pedestrians, bicycles, or automobiles to inform urban 'dashboards' and publicsector decision-making. In the supermarket aisle, faces are tracked, actions are monitored, and movements are traced. Mobile phone communications, emails, and other non-encrypted (and even supposedly encrypted) movements of information are exposed to new forms of commercial and state surveillance, thereby creating new stores of data that can be used to 'profile' and/or target/prosecute certain individuals or groups. Indeed, the worry for some is that new forms of 'data determinism' are emerging, in which individuals are not profiled and judged on the basis of what they have done but also based on predictions of what they might do in the future. The algorithms making these predictions are far from perfect because they operate using in-built biases relating to race, ethnicity, gender and sexuality, and yet are black-boxed and lack meaningful oversight and remediate procedures (Rameriz 2013). Data 
stores are being repurposed, used in ways they were never intended, and hoarded as a speculative measure to capture value in the future.

In short, because so much of daily life creates digital markers and leaves analysable data trails, humans are now exposed to the prospect of data grabbing whether they like it or not; whether they have implicitly signed up to it, or not; whether they know it, or not. And these data can be used in all kinds of ways to affect everyday lives, sometimes in positive ways, but also for the purposes of nudge and control. The pervasive and proliferating platforms and all of the constituent units that so many of us are well-accustomed to using, as well as the many other forms of surveillance monitoring daily life to which we are exposed, signifies that 'grabbing' is one of the most prominent dynamics and outcomes of the algorithmic age.

\section{Slow computing}

Against this overall backdrop, we now elaborate upon and explore two sides of what we refer to as 'slow computing,' which we argue is a suitable way to characterise and practice resistance in the algorithmic age. Resistance, we argue, takes the form of slowing down one's rate of participation in processes of social acceleration and temporal reconfiguration and performing intricate 'dances' around and within the proliferating platforms and constituent units of data grabbing infrastructures. Neither of these moves is problem-free, with both practices posing difficulties for technology users. Nevertheless, slow computing is an option and is increasingly necessary if technology users want to compute on their terms.

\section{Slowing down}

Here we consider the temporal component of slow computing as a means to reduce time compression, fragmentation, densification and stresses. In effect, slow computing is possible because technology users have options to slow down their rate of participation in social acceleration. At issue are everyday decisions about how users interact with the variety of technologies around them. We highlight moves such as switching off home Wifi routers for set periods each day; less frequently 'checking in' on social media or only pursuing one or two (admittedly, probably quite long) email sessions per day; reserving computational-free leisure time, such as refusing to answer work email or phone calls at weekends or outside work hours; maintaining scheduled, device-free meal times; organising pre-arranged meetings rather than doing so on-the-fly; choosing to buy and use non-smart or analogue electrical goods; opting to wait in line and have grocery items scanned by a member of staff, 
rather than using self-scanning facilities; deleting (or not installing in the first place) 'apps' providing immediate access to train or bus times; collecting goods purchased online in-store rather than having them delivered; etc. In other words, there is scope to re-build life around social and clock time rather than network time, and older, slower practices rather accelerated ones. The key point, then, is that technology can remain a part of daily life and some of the effects of social acceleration can be ameliorated if users decide to adjust or tweak their practices in ways that slow down their rate of participation.

Put differently, slow computing entails a sequence of identifying contingencies moments in life when refusing to play a part in hyper-communication, -coordination, consumption, -production would not negatively impact on others - and deciding to participate in social processes at a slower rate than might be otherwise expected. Although the impression given by the speeding-up of social life can be that 'running to stand still' is increasingly necessary, daily reflexive audits of the numerous contingencies within the chains of social relations connecting us to others can reveal numerous opportunities for slowing down. In play here is a new ethics of time that requires individual and collective reflection, conceivably enrolling institutional structures, on the nature of time sovereignty in the contemporary context. Technological developments invite us to lose control over our personal time: always-on Wifi at home or facilities to quickly purchase (impulse) goods in the supermarket discourage the development of such an ethics. The technological prompt, it seems, is always to get more done in a short amount of time. Slow computing, we argue, requires 'reaching for the emergency brake' (Rosa 2015: 321) in our daily lives, although recognizing at the same time that such a move on its own is not exactly 'radical and revolutionary' (p.322). However, a more provocative scenario might come into view if slowing down is complemented by a second form of resistance.

\section{'Data dancing'}

If slowing down is one component of slow computing, the performance of intricate dances around and within the proliferating platforms and constituent units of data grabbing infrastructures is a second component. At issue here is a different set of everyday decisions about how users interact with technology and the extent to which they seek to protect themselves from data grabbing and subsequent use of these data. For example, practical resistance tactics to data grabbing include: the installation and commitment to desktop operating systems (such as Tails OS or Qubes OS) that leave minimal data trails; the use of custom ROMs on smartphones that do not require installing Google Apps; the use of privacy 
enhancement tools in internet browsers such as ad blockers and other plug-ins to minimize tracking; the use of TOR networks that hide IP addresses; the adoption of encrypted messaging applications such as Signal or Telegram; the complete withdrawal from social media platforms; moving to pay-for-service applications that do not use data-for-service as a business model; the purchase of groceries, train or bus tickets, or other items with cash and without the use of store loyalty cards or 'smart' cards; etc. Beyond practical tactics are political manoeuvers such as campaigning for governance, regulatory and legal interventions limits; advocacy for privacy-by-design; promoting open source solutions that do not harvest/monetize data; and encouraging companies to self-regulate or adopt privacy-ascompetitive advantage strategy.

The key point here is that users increasingly have at their disposal collective political power and ways of taking advantage of computing technologies, whether to complete specific tasks quickly or communicate at-a-distance, while evading data grabbing infrastructures. In other words, slow computing entails 'data dancing,' via which users opt to negotiate diverse technological worlds or ecosystems on their terms, albeit with a recognition that doing so may present numerous inconveniences (installing a custom ROM, for example, can be timeconsuming and some 'apps' will not work smoothly). Although options on smartphone operating systems, to take one example, increasingly encourage us to 'share' data and therefore take part in a data-revealing game of 'tickles' (re-tweets, favourites, likes) that enable firms to profile our tastes or identities, individual and collective action is making it possible to identify and pursue alternative pathways that reduce our exposure to data grabbing. In play here is an emerging data ethics that comes to light most frequently when an individual or collective (inconveniently) alters how they participate in chains of social relations, or when questions about data sovereignty are posed in an institutional setting.

The digital revolution asks users to generate data and abandon any control over what will (or can) be done with those data: Google or Facebook establish huge market capitalizations (and political influence) while promising not to be evil and discouraging critical reflection on the nature of data grabbing. The invitation is always to expose one's self, to work away at generating data while online. Slow computing, we argue, requires finding ways of resisting these specific processes of data colonialism as well as data grabbing processes more generally. New and conceivably more radical and revolutionary scope exists to create alternative algorithmic futures by dancing around platforms, navigating cyberspace, or supporting and installing technologies that empower slow computing. We have slow computing options, then, thanks in large part to diverse forms of networked cooperation that 
consistently create counter-technologies that undermine dominant tendencies and present scope to pursue slow computing practices.

\section{Persistent obstacles}

Obviously, however, slowing down and data dancing will always confront persistent obstacles. We can applaud slow computing efforts, therefore, but not without recognizing that slow computing is to a large extent a utopian and ultimately unrealizable state. Per the grid in Figure 1, slow computing might be conceptualized in the bottom, left-hand corner, whereby an individual can compute, but refuses to accelerate to the extent society demands and evades all data grabbing architectures. Such a scenario remains utopian, at least for now. Regarding slowing down, for example, one major reason is that staying in employment increasingly requires participating in accelerating workflow systems with round-the-clock email communications, Slack messages, or hyper-flexible zero-hours contracts that require employees to remain on standby. An individual might manage to achieve some slowing down, but persistent obstacles confront a great many, if not the majority of people in work today. Then, with respect to data dancing, it is necessary to reiterate that data grabbing is not only about users actively generating data but also occurs via passive data generation, for example when someone steps onto the street today and has their movements or face exposed to software. And although there are options to resist data grabbing on a personal device, work-based devices are unlikely to offer such opportunities. In effect, there are varieties of constraints on slow computing, which results in a maximum viable threshold of slow computing; that is, a point at which slow computing cannot continue because doing so would require overcoming insurmountable governmental or institutional barriers.

Moreover, a critical feature in understanding the persistent obstacles to slow computing involves technology firms and the variety of ways they can tweak goods and services to reduce the scope that users might have to slow down or dance around platforms and units. Services from firms such as Google, for example, can hide lines of code that send locational data despite users believing they are not sharing such information (Khandelwal 2017). Software updates override adjustments to settings, install new applications, or tweak the arrangement of individual units to prompt certain types of behaviour. Beyond the traditional suite of technology goods and services, manufacturing and services firms also roll out new products that demand frequent interaction and/or enable them to gather data. Much as any one individual might like to practice slow computing and resist the dominant tendencies, (some) firms appear to be well aware of the need to remain one step ahead of 
resistance, although the line-up of product failures demonstrates that firms have certainly not perfected their approaches.

Perhaps the upshot here is that slow computing will always produce a blend of realities, with some points in space-time resulting in 'accelerated deviation' from slow computing (when there is no slowing down but significant dancing), others yielding a 'grabbed deviation' (when there is significant slowing down but little evasion), and then slow computing's opposite: a perfectly-realizable state of 'full deviation' from the ideal of slow computing, when an individual (or indeed a full society) participates fully in social acceleration and fully accepts the invitation to participate in data grabbing architectures.

Figure 1: Slow computing amidst acceleration and grabbing

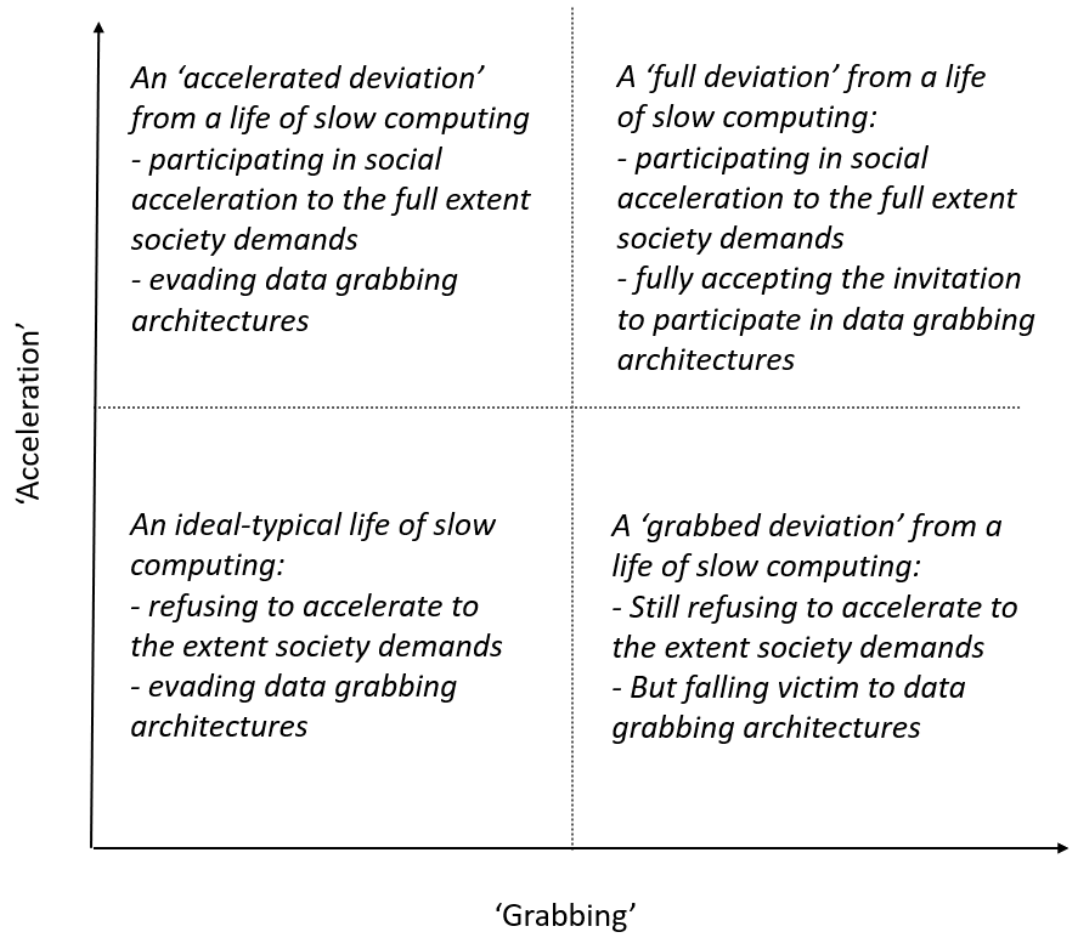

\section{Conclusion}

We have highlighted in the preceding discussion that slow computing has broad significance in the context of the algorithmic age. As reflected by the diverse backgrounds and interests of the contributors at the Slow Computing workshop, a wide array of conceptual and methodological questions springs forth when we ask how individuals, groups, or indeed governments might try to resist the power and players shaping the technological worlds that increasingly tie us all together. Whether by deliberately slowing down one's rate of 
participation in processes of social acceleration, or performing intricate dances around and within the proliferating platforms and constituent units of data grabbing infrastructures, users of today's technologies have slow computing options. And because these actions almost always involve techniques or instruments worked on, and set loose for free, by distant actors determined to enable practices akin to slow computing, one virtue of shining a light on resistance in the algorithmic age is the scope it presents researchers to begin tracing the new routes and directions of an impressive, potentially global, and certainly ambitious form of networked cooperation that aims to embrace technology but not in a blithe uncritical manner. Slow computing draws on and demands further ongoing, flexible, and astute networked cooperation. Passing between those who engage in networked cooperation to enable slow computing are emerging forms of knowledge about, and shared experiences of living differently with, technology - such as the practical tactics and technologies detailed above.

But there also are exciting new exchanges of technological imaginaries that continue to provoke coders, engineers, curators, and users to find new ways of adjusting technological life in ways that equip us all to pursue slow computing practices in the specific ways we desire. Within online communities and the numerous spaces of exchange, new ideas are taking shape about what might be the possible lives and meanings of devices, sensors, lines of code, platform or units. For all the attention given to the undeniably powerful imaginaries of a Facebook or Alphabet - imaginaries of new societies where they will have extraordinary scope to be evil, even if their purported mission is not to do so - we call here for further multi- and inter-disciplinary research on slow computing practices: on the nuances thereof, the networked cooperation facilitating, and the technological imaginaries embedded within, slow computing.

This project requires normative and political thinking concerning the kind of algorithmic future we want to create and live in. The core issue is how should society and states respond collectively through regulation, legislation, education, and training? A key aspect of this work is to elaborate upon an ethics of acceleration and grabbing; an ethics of big data, algorithmic governance, machine learning, artificial intelligence, automation and the diverse technologies and practices that increasingly shape everyday life that maps out their moral contours and actions, and envisions more just alternatives. A technological future exists which is radically different from the dominant vision portrayed in movies such as $\mathrm{Her}$, TV shows such as Black Mirror, or in the PR blurbs of technology firms. But it seems to us that this future can only become a reality if we - as individual users, groups, or citizens electing governments - think seriously about and then try to pursue slow computing. 


\section{Acknowledgement}

The research for part of this paper has been conducted under the Programmable City project, funded by a European Research Council Advanced Investigator award (ERC-2012-AdG323636-SOFTCITY).

\section{References:}

Amoore L (2013) The Politics of Possibility: Risk and Security Beyond Probability. Durham, NC: Duke University Press.

Crang M (2007) Speed= distance/time chronotopographies of action. In: Hassan, R. \& Purser, R. 24/7: Time and Temporality in the Network Society. Stanford, CA: Stanford University Press, pp. 62-88.

Datta, A. and Shaban, A. (2017) Slow: Towards a decelerated urbanism. In Datta, A. and Shaban, A. (eds) Mega-Urbanization in the Global South: Fast cities and new urban utopias of the postcolonial state. Routledge: London. pp. 205-220.

Deleuze, G. (1992) Postscript on the societies of control. October 59 3-7

Elwood, S. and Leszczynski, A. (2011) Privacy reconsidered: reconsidered: New representations, data practices, and the geoweb. Geoforum 42: 6-15.

Ettlinger, N. (2003) Cultural economic geography and a relational and microspace approach to trusts, rationalities, networks, and change in collaborative workplaces. Journal of Economic Geography 3(2): 145-171.

Gillespie, T. (2014a). The relevance of algorithms. In T. Gillespie, P.J. Boczkowski and K.A. Foot (Eds) Media Technologies: Essays on Communication, Materiality, and Society. Cambridge, MA: MIT Press, pp.167-93.

Green, N. (2002) On the move: Technology, mobility, and the mediation of social time and space. The Information Society 18(4): 281-292.

Hassan, R. and Purser, R. (2007) 24/7: Time and Temporality in the Network Society. Stanford, CA: Stanford University Press.

Khandelwal, S. (2017) Google Collects Android Location Data Even When Location Service is Disabled. The Hacker News, Nov 21. Available at: https://thehackernews.com/2017/11/android-location-tracking.html

Kitchin, R. (2016) Getting smarter about smart cities: Improving data privacy and data security. Data Protection Unit, Department of the Taoiseach, Dublin, Ireland. 
http://www.taoiseach.gov.ie/eng/Publications/Publications_2016/Smart_Cities_Report_Ja nuary_2016.pdf

Kitchin R (2017) Thinking critically about and researching algorithms. Information, Communication and Society 20(1): 1-14.

Kitchin, R. and Dodge, M. (2011). Code/Space: Software and Everyday Life. Cambridge, MA: MIT Press.

Koops, B.J. (2011) Forgetting Footprints, Shunning Shadows: A Critical Analysis of the 'Right to Be Forgotten' in Big Data Practice. SCRIPTed 8(3): 229-256.

Kramer ADI, Guillory JE and Hancock JT (2016) Experimental evidence of massive-scale emotional contagion through social networks. Proceedings of the National Academy of Sciences 111(24): 8788-8790.

Lyon, D. (2007) Surveillance Studies: An Overview. Polity, Cambridge.

Manyika, J., Chiu, M., Brown, B., Bughin, J., Dobbs, R., Roxburgh, C. and Hung Byers, A. (2011) Big Data: The Next Frontier for Innovation, Competition, and Productivity. McKinsey Global Institute.

McIlwain C (2017). Racial formation, inequality and the political economy of web traffic. Information, Communication \& Society 20(7): 1073-1089.

Miele, M. and Murdoch, J. (2002) The practical aesthetics of traditional cuisines: slow food in Tuscany. Sociologica Ruralis 42(4): 312-328.

Mountz, A., Bonds, A., Mansfield, B., Loyd, J., Hyndman, J., Walton-Roberts, M., Basu, R., Whitson, R., Hawkins, R., Hamilton, T. and Curran, W. (2015) For slow scholarship: A feminist politics of resistance through collective action in the neoliberal university. ACME: An International Journal for Critical Geographies 14(4): 1235-1259.

Pasquale, F. (2015). The Black Box Society: The Secret Algorithms That Control Money and Information. Harvard University Press, Cambridge, MA.

Rameriz, E. (2013) The privacy challenges of big data: A view from the lifeguard's chair. Technology Policy Institute Aspen Forum, 19 August. http://www.ftc.gov/speeches/ramirez/130819bigdataaspen.pdf (last accessed 11 October 2013)

Rosa, H. (2003) Social acceleration: Ethical and political consequences of a desynchronized high-speed society. Constellations 10(1): 3-33.

Rosa, H. (2015) Social Acceleration: A New Theory of Modernity. Columbia University Press, New York. 
Singer, N. (2012) You for Sale: Mapping, and Sharing, the Consumer Genome. New York Times, $17^{\text {th }}$ June, http://www.nytimes.com/2012/06/17/technology/acxiom-the-quiet-giantof-consumer-database-marketing.html (last accessed 11th October 2013)

Thatcher. J., O’Sullivan, D., and Mahmoudi, D. (2016) Data colonialism through accumulation by dispossession: New metaphors for daily data. Environment \& Planning D: Society and Space 34: 990-1006.

Wacjman, J. (2015) Pressed for Time: The Acceleration of Life in Digital Capitalism. University of Chicago Press, Chicago. 